\title{
Concrete and Culture. A material history
}

\section{Julio César Moreno Moreno}

Una mirada nueva, desde un punto de vista singular, sobre un material suficientemente conocido y habitual como es el hormigón, es lo que nos plantea Adrian Forty en su libro. Lo hace presentándolo, más allá de su propia condición, como elemento de creación y transmisión de cultura; para ello, establece una analogía entre dicho material y el lenguaje. En dicho símil, pone de relieve que el lenguaje es un medio productor y transformador de cultura, más allá de su función principal de comunicación.

A fresh look from a remarkable perspective at a material as ubiquitous and commonplace as concrete - this is what Adrian Forty proposes in this book. Constructing an analogy between the material and language, he presents concrete as something that goes beyond what it is - as an element for the creation and transmission of culture. In this analogy, he emphasizes that in addition to its principal function as a means of communication, language is a means for producing and transforming culture.

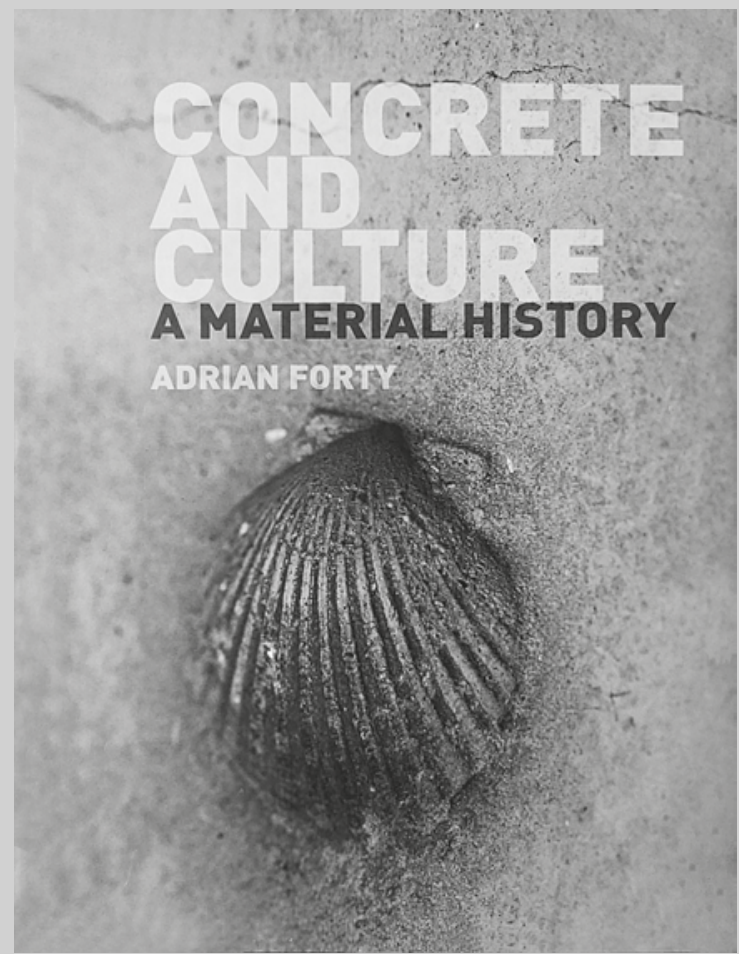

Fig. 01.

Portada del libro de Concrete and culture. A material history. Adrian Forty. London: Reaktion Books, 2012 
Universidad Politécnica de Madrid

jcesar2@jcesar.org
Ya, en su anterior libro Words and Buildings, Forty había utilizado la analogía entre lenguaje y arquitectura, deteniéndose en el vocabulario empleado en arquitectura desde la modernidad, y, en menor medida, recorriendo esa vinculación a lo largo de toda la historia. Buen exponente de esta forma de aproximación puede verse en el capítulo de dicho texto, titulado Metáforas del lenguaje, donde indica cómo desde el siglo XVIII se han extrapolado aspectos teóricos de la lingüística para explicar, tanto aspectos parciales como generales de la arquitectura. Esta relación analógica reforzaría el entendimiento de la arquitectura como medio de expresión y transformador de cultura.

Las indagaciones sobre el vocabulario de la arquitectura moderna y las metáforas del lenguaje ayudaron, sin duda, al autor en su búsqueda sobre las relaciones entre el hormigón y la cultura. Dicho paralelismo alienta su convicción de que, más allá de su condición material y física, el hormigón tiene una condición inmaterial o metafísica que se incorpora e interactúa con el mundo de la cultura de forma activa.

Para esta investigación, Forty se sirvió de otros aspectos de su anterior libro; de manera que muchos de los términos que define en Words and Buildings como el vocabulario esencial de la arquitectura moderna se corresponden con los capítulos de Hormigón y cultura. Lo introduce en este libro en forma de oposiciones: un concepto y su contrario coexisten sin excluirse en la naturaleza cultural del hormigón. La mayor parte de capítulos se ocupan de una de estas oposiciones, que se anuncian en sus respectivos títulos.

Aparece como idea fundamental del libro la consideración del hormigón como medio que sirve a la producción de cultura a muy diversas escalas y con las más variadas implicaciones. De hecho, al principio de la introducción el autor ya lo enuncia, y añade que por su carácter universal y ubicuo se parece al lenguaje. Sostiene que, como el lenguaje, el hormigón se emplea en cualquier parte del Mundo en muy variadas formas, y que cualquier persona se encuentra habitualmente en contacto con él como soporte de su vida diaria. Según afirma, el que el hormigón sea un medio tan difundido implica que escapa al control de las disciplinas de la ingeniería y la arquitectura, poniendo de relieve - con abundantes datos y cifras-que se emplea muy mayoritariamente por manos no expertas ni profesionalizadas.

Existe un precedente que puede servir para entender mejor las tesis de Forty en cuanto a la relación entre cultura y medios técnicos de construcción. Se trata del conocido texto de Adolf Loos titulado "The plumbers", que fue publicado en 1989. En él, Loos enuncia una nueva definición de cultura a principios del siglo XX. Es interesante, en relación con el texto de Adrian Forty, el que esa definición le llega a Loos de una persona que no pertenece a ningún ámbito profesionalizado o disciplinar. Según ese enunciado, el rasgo esencial que caracterizaba ese nuevo estado de la cultura es la "plomería", entendida como el conjunto de las instalaciones domésticas que permitían la evacuación de aguas residuales y el suministro de agua y energía. Lo que era, precisamente para él, más importante era que todas las viviendas en Estados Unidos contaran con esas instalaciones, a diferencia de lo que ocurría en cualquier parte de Europa. Para él no era un aspecto cualquiera de la cultura, lo consideraba un medio técnico que formaba parte activamente de ella, permitiendo que se desarrollara y manifestara, planteamiento muy en consonancia con la interpretación que Forty hace del hormigón. Con implicaciones políticas evidentes, mencionaba expresamente que esas instalaciones permitían una higiene personal igualitaria, imprescindible para la vida colectiva de la sociedad de masas. La relación entre ambos textos es aún más directa por la mención que hace Loos del hormigón, cuando afirma que la piedra no es imprescindible para la vida moderna porque se puede sustituir sin problema por el hormigón.

Aunque Forty no define explícitamente en ningún momento cómo entiende ese papel de medio para la cultura que cumple el hormigón, a lo largo del texto va clarificando una multitud de aspectos a los que se refiere. Abarca desde los ámbitos más cerrados y disciplinalmente especializados hasta los más amplios y abiertos de la cultura de masas. 
Como ejemplo de esto último, son interesantes los términos o frases hechas que recoge del lenguaje popular en diversos lugares. Muestra cómo expresan ciertos aspectos particulares muy precisos y cómo en su conjunto revelan las profundas implicaciones culturales de este material. Por ejemplo, menciona como en Méjico llaman "castillos de esperanza" a las armaduras metálicas que se dejan vistas apuntando hacia el cielo sobre el techo de las viviendas: una denominación que recoge la actitud de espera para poder continuar construyendo las plantas superiores cuando el destino traiga tiempos mejores. Otra expresión que recoge Forty es to concrete over. Está muy extendida, con equivalencias en varios idiomas. Por ejemplo, en castellano se dice hormigonar o popularmente 'encementar' para expresar que se borra todo rastro de naturaleza preexistente sobre un terreno.

Forty utiliza abundantes referencias a otros medios que sirven a la cultura en todo el texto, muchos de ellos son los de comunicación de masas o el arte. Con numerosas menciones al cine, la fotografía, el arte o la literatura, que pone en relación con diversos aspectos del hormigón, el autor presenta este material como un medio de expresión con la misma capacidad que los demás de influir en la cultura.

Quizá basado en analogías entre lenguaje escrito y hormigón, las obras que recoge son presentadas como documentos a interpretar, en un sentido cercano al concepto de 'lectura de paramentos' empleado en arqueología. Planteado así, se podría decir que cada obra de hormigón porta determinada información que el autor logra descodificar o interpretar. Pone en relación estas interpretaciones mediante diversos hilos argumentales, lo que da una cualidad al texto que lo acerca al campo de la literatura narrativa; de manera que pese a la gran cantidad de información que contiene, el libro cuenta una historia muy fácil de leer.

Probablemente sea esa la razón de que las ilustraciones tengan la misma importancia que los textos. En su mayoría son fotografías y, de ellas, buena parte han sido tomadas por el autor en sus muchos viajes dedicados a documentar esta investigación. Algunas no se comentan, como las que aparecen al inicio de cada capítulo. Las presenta para que hablen por sí mismas, como si fueran obras de arte con tan solo un título como texto asociado. De esta manera, tanto la fotografía como el hormigón se interpretan como medios de comunicación con la misma influencia y relevancia en la cultura, que se habrían desarrollado juntos desde su origen simultáneo en la década de 1830.

Otra cuestión importante del libro es cuánto tiene de estudio histórico. El subtítulo introduce la palabra historia, lo que nos llevaría a entender que es una historia del hormigón. Forty aclara que no lo ha planteado como una historia al uso del material, argumentando que ya hay bibliografía solvente al respecto. Afirma que, en todo caso, sería una historia del medio, y que más que escribir una historia del medio ha estudiado un medio que tiene historia.

En cuanto a los contenidos, el autor aborda desde diferentes ángulos la multitud de aspectos que componen el fenómeno del hormigón armado desde su origen en la década de 1830 hasta nuestros días. Lo hace en forma de argumentos contrapuestos a la vez que integrados. Así, los primeros ocho capítulos se ocupan cada uno de un par de opuestos. Deja el autor el capítulo nueve para hablar de las grandes afinidades que encuentra entre el hormigón y otro gran medio de la cultura: la fotografía. Por último, en el capítulo diez, desarrolla la idea de que existe un renacimiento del hormigón.

En su analogía con el lenguaje, dichas oposiciones corresponderían a la polisemia del hormigón como medio de comunicación: el hormigón sería capaz de expresar con un mismo significante -su realidad material construida- distintos significados, muchas veces contrapuestos.

Concluye afirmando que la influencia mutua entre hormigón y cultura seguirá siendo igual de intensa en el futuro, por mucho que los cambios en las circunstancias sociales, políticas, económicas o ambientales hagan evolucionar dicha relación de interdependencia. 